\title{
Ofis Çalışanlarında Çalışma Postürü, Kas İskelet Sistemi Rahatsızlıkları, Bel Ağrısına Bağlı Özürlülük Düzeyi ve Sağlıkla İlgili Yaşam Kalitesinin İncelenmesi
}

\author{
Examination of Working Posture, Musculoskeletal System Disorders, Disability Level Due to Lumbar \\ Pain and Health Related Quality Of Life in Office Workers
}

\author{
Fadime KÜÇÜK ${ }^{1}$, Seren DÜZENLİ ÖZTÜRK ${ }^{2}$, Hande ŞENOL ${ }^{3}$, Mehmet ÖZKESKIN $^{4}$ \\ ${ }^{1}$ Dr. Öğr. Üyesi, Fizyoterapi ve Rehabilitasyon Bölümü, Sağlık Bilimleri Fakültesi, Okan Üniversitesi, İstanbul, Türkiye \\ ${ }^{2}$ Uzm. Fzt., Disiplinlerarası Sinir Bilimler Anabilim Dalı, Sağlık Bilimleri Enstitüsü, Ankara Üniversitesi, Ankara, Türkiye \\ ${ }^{3}$ Biyoistatistik Uzmanı, Biyoistatistik Anabilim Dalı, Tıp Fakültesi, Pamukkale Üniversitesi, Denizli, Türkiye \\ ${ }^{4}$ Yrd. Doç., Fizyoterapi ve Rehabilitasyon Bölümü, Sağlık Bilimleri Fakültesi, Okan Üniversitesi, İstanbul, Türkiye
}

\section{öz}

\begin{abstract}
Amaç: Bu çalışmanın amacı, ofis çalışanlarının çalışma postürü, kas iskelet sistemi rahatsızlıkları, bel ağrısına bağlı özürlülük düzeyi, sağlıkla ilgili yaşam kalitesinin incelenmesi, aralarındaki ilişkinin belirlenmesidir. Gereç ve Yöntem: Araştırmaya toplam 213 ofis çalışanı dâhil edildi. Ofis çalışanları, Ovako Çalışma Postürü Analiz Sistemi, Cornell Kas İskelet Sistemi Rahatsızlığı Anketi, Oswestry Özürlülük Anketi ve Nottingham Sağlık Profili ile değerlendirildi. Sonuçlar: Oswestry Özürlülük Anketi ile omurga, alt ekstremite, üst ekstremite ağrı sıklığı, ağrı şiddeti ve ağrıya bağlı işin engellenmesi arasında ileri derecede anlamlı ilişkiler bulundu( $p=0,000, r=0,328-0,505)$. Nottingham Sağlık Profilinin enerji, ağrı, fiziksel hareketlilik, uyku, emosyonel reaksiyonlar, sosyal izolasyon alt parametreleri ile omurga, alt ekstremite, üst ekstremite ağrı sıklığı, ağrı şiddeti, ağrıya bağı işin engellenmesi ve bel ağrısı arasında ileri derecede anlamlı ilişkiler bulundu $(p=0,020-0,000, r=0,159-0,671<0,005)$. Tartışma: Kadın ofis çalışanlarının bel ağrısına bağlı özürlülük düzeyi, erkeklerden daha fazla bulundu. İlişki analizleri incelendiğinde, bel ağrısına bağlı özürlülük düzeyi ile kas iskelet sistemine bağlı ağrı sıklığı ve şiddeti ile ilişkili olduğu bu durumun işi engellediği görüldü. Ayrıca bel ağrısına bağlı özürlülük düzeyi; sağlıkla ilgili yaşam kalitesi ile de ilişkili bulundu. İleride yapılacak çalışmalarda, ofis çalışanlarının doğru çalışma postürü konusunda kapsamlı eğitim verilmesi ve yapılacak ergonomik düzenlemelerin sağlıkla ilgili yaşam kalitesine etkisi üzerine etkisinin araştırılması gereklidir.
\end{abstract}

Anahtar Kelimeler: Ofis Çalışanı; Postür; Kas-İskelet Bozuklukları; Bel Ağrısı; Özürlülük

\section{ABSTRACT}

Purpose: The aim of this study is to determine the relationships between posture of work, musculoskeletal system disorders, low back pain related disability, and health-related quality of life (HRQoL) of office workers. Material and Methods: Total of 213 office workers were included in the study. Office workers were analyzed by Ovako Working Posture Analysis System, Cornell Musculoskeletal System Discomfort Survey, Oswestry back pain disability questionnaire (ODQ), Nottingham Health Profile (NHP). Results: Significant correlations were found between ODQ and spine, lower extremity, upper extremity pain frequency, severity and pain-related job inhibition ( $p=0,000, r=0,328-0,505)$. Significant correlations were found between all sub-parameters of NHP and spine, lower-upper extremity pain frequency, severity, pain-related work inhibition and back pain $(p=0,020-0,000, r=0,159-0,671<0,005)$. Conclusion: The level of disability of female office workers was higher than that of men. It was found that the level of disability related to low back pain was associated with the frequency and severity of pain due to the musculoskeletal system, which prevented the work. Also level of disability due to low back pain was also related to HRQoL. In future studies, it is necessary to give comprehensive training on the right work posture and study the impact of ergonomic regulations on HRQoL.

Key Words: Office Worker; Posture; Musculoskeletal Disorders; Low Back Pain; Disability 
Günümüzde teknolojinin ilerlemesiyle birlikte ofislerde çalışanlarının sayısında artış olmaktadır. Hareket etmek üzere programlanmış olan insanoğlunun uzun süreler statik ve sabit pozisyonlarda kalması sağlık problemlerine neden olmakta, yaşam kalitesini olumsuz yönde etkilemektedir. Literatürde ofis çalışanlarının; tüm gün statik postürde çalışmak zorunda kalmalarına bağlı olarak bel ağrısı görülme sıklığı ve buna bağlı özürlülük düzeyi artmaktadır (Janwantanakul, Pensri, Moolkay ve ark, 2011). Sekiz saatten fazla bilgisayar kullanan her 10 kişiden 8'inde bel ağrısı görülmektedir. Bel ağrısı için tıbbi harcamalar yüksek olmasına rağmen, işe devamsızlık oranının artışı, üretkenliğin azalması gibi gizli maliyetlere de dikkat edilmelidir (Rodriguez-Blanco, Fernández-SanMartin, Balagué-Corbella, ve ark, 2010). İspanya'da her bir bel ağrısında işe gelememe süresi ortalama 21,9 gün olarak bildirilmiştir (Gonzalez Viejo ve Condon Huerta, 2000). Kore'de 143 ofis çalışanı üzerinde yapılan bir çalışmada; aşırı kilolu ve obez ofis çalışanlarının, normal kilolu ofis çalışanlarına göre, aşırı iş yükünden dolayı daha fazla endişeli ve sağlıkla ilgili yaşam kalitesinin mental alt skorunun daha düşük olduğu bildirilmiştir(DeokJu Kim ve ark, 2015). Uzun süre statik postürde bilgisayar başında çalışmanın, özellikle üst trapez ve servikal ekstansör kaslarda gerginlik artışına bağlı olarak kronik boyun ağrısını arttırdığı bildirilmiştir (Szeto, Straker ve O'Sullivan, 2009; Johnston, Jull, Souvlis, ve ark, 2008).

Lee ve ark; yaş ortalaması, iş deneyimi, çalışma süresi, günlük bilgisayar başında geçirilen süre açısından aralarında fark olmayan 120 erkek ve 120 kadın ofis çalışanının kas iskelet sistemi şikayetleri, subjektif semptomları, memnuniyet düzeyi ve cinsiyete göre farklılıklarını araştırmıştır. Ofis çalışanlarının \% 57.1'inin muskuloskeletal rahatsızlıklara bağlı ağrıya sahip belirtilere sahip olduğu, en çok belirtinin görüldüğü vücut kısmı ise boyun ve omuz bölgesi olarak belirtilmiştir. Daha sonra ise sırasıyla; omuz, sırt, el / el bileği / parmaklar, bacak / diz / ayak bölgelerini kapsadığı bildirilmiştir. Ağrı şiddeti açısından en fazla boyun ve omuz bölgesinin etkilendiği fakat cinsiyetler arasında fark olmadığı belirtilmiştir. Kadınlarda, erkeklerden farklı olarak kas iskelet sistemi belirtilerinin en sık görüldüğü bölgeler el / el bileği / parmaklar bölgesi olduğu fakat ağrı şiddeti açısından cinsiyetler arasında fark olmadığı bulunmuştur (Lee, Park, Jeong, 2017). Ardahan ve ark ise bilgisayar kullanan ofis çalışanlarında yaptıkları çalışmada, kas-iskelet sistemi rahatsızlıklarının en çok, boyun, sırt, bel, sağ omuz ve sol omuz bölgelerinde olduğunu belirtmişlerdir(Ardahan, Simsek, 2016). Cho ve ark ise yüksek iş yüküne sahip bilgisayar kullanan 203 ofis çalışanında kas iskelet sistemi rahatsızlıklarının sırasıyla en çok boyun, omuz, boyun, üst sırt bölgelerinde kas iskelet sistemi belirtilerinin olduğu, kadınlarda omuz bölgesine ait şikayetlerin erkeklerden daha fazla olduğu ve bunların psikolojik stres faktörleriyle ilişkili olduğunu belirtmişlerdir (Cho, Hwang \& Cherng 2012).

Literatürde birçok çalışmada, ofis çalışanlarında kas iskelet sistemi rahatsızlıklarının azaltılması için ofis ortamında yapılması gereken ergonomik düzenlemeler ile bu rahatsızlık riski arasındaki ilişki incelenmiştir (Gerr, Monteilh ve Marcus, 2006; Gerr, Marcus ve Monteilh, 2004). Bilgisayar kullanan ofis çalışanlarında ofisteki bilgisayar klavyesinin yüksekliğini azaltmak veya dirsek seviyesinin altına düşürmek, kolları masa üzerinde veya sandalye kolluklarında dinlendirmek şeklinde yapılabilecek ergonomik düzenlemelerin boyun, omuz kuşağı bölgesindeki kas iskelet sistemi rahatsızlıklarını oluşturma riskini azalttığı bildirilmiştir. Genel olarak, günlük veya haftalık bilgisayar kullanımı saatlerinin artması, boyun ve omuz bölgesi rahatsızlıklarından çok el ve kol rahatsızlıkları ile ilişkili olduğu bulunmuştur. Klavye kullanırken artmış el bileği ekstansiyonunun el ve kol rahatsızlıklarını arttırdığı kanıtlanmıştır (Gerr, Marcus ve Monteilh, 2004).

Ofiste bilgisayar kullanımı, postür, kas iskelet sistemi rahatsızlıkları arasındaki ilişkiyi inceleyen 39 epidemiyolojik çalışma incelenmiştir. El ve kol rahatsızlıkları ile bilgisayar başında geçirilen süre arasındaki ilişki en tutarlı bulgu olarak gösterilmiştir. Özellikle klavyenin dirsek seviyesinin altında olması, baş rotasyonunun azaltılması, kolların dinlendirilmesinin boyun/omuz rahatsızlıklarını azalttığı, klavye kalınlığının ve el bileği ulnar deviasyonun azaltılmasının ise el/kol rahatsızlıklarını azalttığı bulunmuştur. Ayrıca bu tür gözlemsel çalışmalarda, farklı metodolojik eksikliklerin olduğu, olgu örneklerinin evreni tam temsil etmediği, sağlık sonuçları ve ölçümlerle ilgili bias olduğu, neden ve sonuç etkisinin tersine çevrildiği ve heterojen sonuçların gözlemlendiği sonucuna varılmıştır(Gerr, Monteilh ve Marcus, 2006; Gerr, Marcus ve Monteilh, 2004).

Ofis çalışanlarında, bel ağrısı, kas iskelet sistemi rahatsızlıkları, iş verimliliği üzerinde işe ara vermenin etkilerini inceleyen sistematik derlemede; çalışmalarda bahsedilen iş süresinin 5 dakika- 2 saat arasında değişen, işe ara verme süresinin ise 20 
saniye- 30 dakika arasında değişen heterojen bir yapıya sahip olduğu belirtilmiştir. Kas iskelet sistemi rahatsızlıklarının önlenmesinde, işe ara vermenin etkinliğini destekleyen düşük kaliteli kanıtların olduğu, iş verimliliği üzerinde işe ara vermenin olumsuz etkisinin olmadığı, postür değişikliği yaparak aktif işe ara vermenin, iş verimliliğini sağladığı ve bel ağrısını azaltmada etkili olabileceği bildirilmiştir (Waongenngarm, Areerak, \& Janwantanakul;2018).

Çelik ve ark; 528 ofis çalışanının kas iskelet sistemi ağrısı risk faktörlerini araştırmışlar. Kadın ve erkek ofis çalışanlarında, ağrı şikayetinin en çok olduğu bölgeler sırasıyla bel, boyun ve sırt olarak bildirilmiştir. Kas iskelet sistemi ağrısı için risk oluşturan istatistiksel olarak en anlamlı faktörler, işe ara vermeden uzun süre çalışma masası başında oturma, bilgisayar faresi ile klavye arasındaki mesafe, çalışma sırasında başın 45 derece eğimli olması, çalışma sırasında her iki önkolun çalışma masası seviyesinin üzerinde tutulması, günlük egzersiz yapmamak, aşırı stresli işyerinde çalışmak olarak bulunmuştur. Ayrıca sağlıklı yaşam için çalışma ortamında ergonomik düzenlemelerin yapılması gerektiği vurgulanmıştır (Celik, Celik, Dirimese,2017).

Bu çalışma, ofis çalışanlarının çalışma postürü, kas iskelet sistemi rahatsızlıkları, bel ağrısına bağlı özürlülük düzeyi, sağlıkla ilgili yaşam kalitesinin incelenmesi ve aralarındaki ilişkinin belirlenmesi amacıyla yapılmıştır.

\section{GEREÇ VE YÖNTEM}

Bu çalışma, 2016 Ocak-Eylül ayları arasında Türkiye-İzmir ilinde bulunan İzmir Üniversitesi çalışanları arasında gerçekleştirilmiş, kesitsel bir çalışmadır. Çalışmanın tanıtımı üniversitenin web sitesinden ortak mail ağı aracılığıyla yapılmıştır ve araştırmayı tanıtan el ilanları dağıtılmıştır. Araştırmaya gönüllü olarak katılmayı kabul eden ofis çalışanları dahil edilmiştir. Ofis çalışanları çalıştıkları ortamda ziyaret edilerek, çalışma postürleri değerlendirilmiştir. Ofis çalışanları, ilgili anketleri araştırmacı yardımıyla doldurmuştur. Çalışmaya katılan ofis çalışanları, çalıştıkları ortamda yalnızca bir kez değerlendirilmiştir. Katılımcıların yaş, cinsiyet, boy, kilo, eğitim, sigara içme durumu, meslek gibi özellikleri, günlük çalışma süresi, günlük sabit oturma süresi ve çalışma yılı anket formuna kaydedilmiştir.

Çalışmanın etik kurul onayı 19/03/2015 tarihinde İzmir Üniversitesi (protokol no: 2015/10) Girişimsel Olmayan Bilimsel Çalışmalar Etik Kurulu'ndan alınmıştır. Çalışmaya katılmadan önce, tüm katılımcıların, Helsinki Deklarasyon Kriterlerine uygun olarak hazırlanmış Bilgilendirilmiş Gönüllü Onam Formunu okuyup, imzalamaları istenmiştir.

Çalışmaya en az 1 yıldır ofis çalışanı olarak görev yapan, 20-50 yaş arasında olan bireyler alınmıştır. Metabolik ve/veya nörolojik bir hastalığı olan, herhangi bir fiziksel ve/veya mental engeli bulunan, spinal kord ve/veya alt ekstremite cerrahisi geçirmiş olanlar, lumbal patolojilerden herhangi birinin tanısını alanlar (lumbal disk hernisi, lumbal spinal stenoz vb.) ile gebeler çalışma dışı bırakılmıştır.

Katılımcıların, ofis çalışanı olarak çalışma hayatı öncesindeki bel ağrılarının varlığı, bununla ilgili tedavi alıp almadıkları sorgulanmıştır. Çalışmamızda çalışma postürü Ovako Çalışma Postürü Analiz Sistemi (OWAS) (Gilkey Keefe, Bigelow ve ark, 2007, Özel ve Çetik, 2010), kas iskelet sistemi rahatsızlıklarının sıklığı ve ağrıya bağlı işin engellenmesi Cornell Kas İskelet Sistemi Rahatsızlığı Anketi (CMDQ) (Erdinç, Hot ve Özkaya, 2011), bel ağrısına ağrıya bağlı özürlülük Türkçe geçerlik ve güvenirliği yapılmış Oswestry Özürlülük Anketi (OÖA) (Yakut, Düger ve Öksüz, 2004), sağlıkla ilgili yaşam kalitesi Nottingham Sağlık Profili (NSP) (Küçükdeveci, Mckenna ve Kutlay, 2000) ile değerlendirilmiştir.

\section{Ovako Çalışma Postürü Analiz Sistemi (OWAS)}

OWAS, çalışanların kas iskelet sistemine ait yüklenme ve kötü postürlerini belirlemeye yarayan, gözleme dayalı, çalışma postürü analiz sistemidir. Bu sistemde, analist gözlem yoluyla sırt, kollar, bacaklar ve yükün 4 dijital kod yardımıyla kaydını tutar (Gilkey ve ark, 2007). Çalışmamızda sırt, üst ekstremite, alt ekstremite ve yük taşıma olarak veriler ayrı ayrı değerlendirilmiştir.

\section{Cornell Kas İskelet Sistemi Rahatsızlığı Anketi (CMDQ)}

Cornell Kas İskelet Sistemi Rahatsızlığı Anketi (CMDQ), Cornell Üniversitesi tarafından geliştirilen, Erdinç ve ark. tarafından Türkçe geçerlik güvenirliği yapılmış bir ankettir(Erdinç ve ark, 2011). CMDQ, son 7 gün içinde, 11 farklı vücut bölgesindeki (boyun, omuz, sırt, üst kol, bel, ön kol, el bileği, kalça, üst bacak, diz ve alt bacak) ağrı ya da rahatsızlığın sıklığını, şiddetini ve iş yapabilme yeteneği üzerindeki etkilerini değerlendirir. Sıklık, şiddet ve ağrıya bağlı işin engellenmesine göre verilen cevapların, ağırlık puanları ayrı ayrı hesaplanır (Hedge, 1994). Çalışmamızda değerlendirme sonuçlarının daha kolay ve anlaşılır 
yorumlanabilmesi için, CMDQ omurga, alt ve üst ekstremite olmak üzere 3 bölümde değerlendirilmiştir.

\section{Oswestry Özürlülük Anketi (OÖA)}

Katıımcıların günlük yaşam aktiviteleri sırasındaki bel ağrısına bağlı özürlülük düzeyi OÖA ile değerlendirilmiştir. OÖA, günlük yaşam aktivitelerini ölçen 10 adet bölümden oluşmaktadır. Bunlar; ağrı şiddeti, kişisel bakım, ağır kaldırma, yürüme, oturma, ayakta durma, uyuma, cinsel yaşam, sosyal yaşam, seyahat ve ağrının değişik dereceleridir. Her bir bölüm 6 soru içerir ve her bölüm 0-5 puan arasında puanlanır (Fairbank, Pynsent, 2000; Yakut ve ark, 2004).

\section{Nottingham Sağılı Profili (NSP)}

Katıımcıların sağlıkla ilgili yaşam kalitesi NSP ile değerlendirilmiştir. NSP, iki bölümden meydana gelen kişilerin kendilerinin cevaplayabileceği kısa ve basit bir ankettir. Bu anket, fiziksel, sosyal ve ruhsal iyilik hali ile ilgili geniş bir tanımlamayı yansıtmaktadır. NSP'nin birinci bölümündeki sorular, kişilerin sağlık statüleri ile iliş̧kili alanlara değinirken, ikinci bölümündeki sorular ise, içinde bulunulan sağlık düzeyinin günlük yaşam üzerindeki etkilerini belirlemeye yöneliktir. NSP'nin birinci bölümü; fiziksel hareketlilik, ağrı, uyku, enerji, sosyal izolasyon ve duygusal reaksiyonlar gibi altı alanı içeren 38 sorudan meydana gelmektedir. İkinci bölümü ise, sağılı düzeyini etkilediği düşünülen yedi alandan oluşmaktadır. Bu alanlar; iş yaşamı, ev işleri, ev hayatı, cinsel yaşam, sosyal yaşam, ilgiler ve tatillerdir. NSP'de katılımcılardan, okudukları ifadelerin kendi durumlarını yansıtıp yansıtmadığına göre cevap vermeleri istenmektedir (Küçükdeveci ve ark, 2000). NSP'nin skorlamasında, 0-100 puan arasında olası sonuçlar elde edilmektedir. Elde edilen skorun, 100 puana yaklaşması düşük düzeyde algılanan sağlık statüsünü ifade etmektedir. NSP'nin ikinci bölümünde herhangi bir skorlama işlemi yapılamamakta, bunun yerine frekanslar ve yüzdeler üzerinden değerlendirmeler yapılmaktadır (Alonso, Anto, Moreno ve ark, 1990).

\section{Istatistiksel Analiz}

Çalışmada elde edilen verilerin istatistiksel analizi, SPSS (Statistical Package for Social Science) versiyon. 16 programıyla yapılmışır. Tanımlayıcı istatistik olarak frekans, yüzde değerler, ortalama, standart sapma kullanılmıştır. Örneklemde dağılım normal olmadığı için sayısal değişkenler arasındaki ilişki Spearman korelasyon testi ile incelenmiştir. Kişisel risk faktörlerinden cinsiyet ve çalışma yılı değişkenlerinin OÖA sonuçlarına etkisi MannWhitney $U$ testi ile karşılaştııılmıştır. İstatistiksel anlamlıık düzeyi $p<0,05$ olarak kabul edilmiştir.

\section{SONUÇLAR}

Çalışmaya 131 'i kadın ve 82'si erkek olan 213 ofis çalışanı dâhil edilmiştir (Tablo 1). Çalışmamıza katılan olguların çalışma yılı, günlük çalışma süresi ve sabit oturma süresi yüzdeler şeklinde gösterilmiştir (Tablo 2).

OWAS sonuçlarına ait yüzdeler verilmiştir (Tablo $3)$.

CMDQ verileri 3 alt bölümde ele alınmıştır. Omurga (boyun, sırt ve bel) verilerinin toplamından, alt ekstremite (kalça, üst bacak, diz ve alt bacak) verilerinin toplamından ve üst ekstremite (omuz, üst kol, önkol ve el bileği) verilerinin toplamından oluşmuştur. Ayrıca katılımcıların ağrı sıklığı, ağrı şiddeti ve ağrıya bağıı işin engellenmesi açısından ayrı ayrı analizler yapıımıştır (Tablo 4).

Tablo 1. Ofis çalışanlarının demografik bilgileri

\section{Ortalama \pm SS}

\begin{tabular}{llc}
\hline Yaş (yıl) & & $32,14 \pm 8,06$ \\
\hline VKi $\left(\mathbf{k g} / \mathbf{m}^{2}\right)$ & & $23,93 \pm 4,1$ \\
\hline \multirow{2}{*}{ Cinsiyet } & kadın & $\mathbf{n ~ ( \% )}$ \\
\hline \multirow{2}{*}{ Sigara } & erkek & $131(\% 61,5)$ \\
\hline & evet & $82(\% 38,5)$ \\
\hline & hayır & $71(\% 33,3)$ \\
\hline
\end{tabular}

(VKI: Vücut Kütle İndeksi, SS: Standart Sapma) 
Tablo 2. Ofis çalışanlarının çalışma yılı, günlük çalışma süresi ve sabit oturma süreleri

\begin{tabular}{lccc}
\hline & & $\mathbf{n}$ & $\mathbf{\%}$ \\
\hline Çalışma yılı & 2 yıldan az & 59 & 27,7 \\
\cline { 2 - 4 } & 2 yıl ve üzeri & 154 & 72,3 \\
\hline Günlük çalışma süresi & 8 saatten az & 85 & 39,9 \\
\cline { 2 - 4 } & 8 saat ve üzeri & 128 & 60,1 \\
\hline Sabit oturma süresi & $0-4$ saat & 41 & 19,2 \\
\cline { 2 - 3 } & $4,1-8$ saat & 128 & 60,1 \\
\hline
\end{tabular}

Tablo 3. Ovako Çalışma Duruşları Analiz Sistemi'ne göre ofis çalışanlarının postürleri

\begin{tabular}{|c|c|c|c|}
\hline${ }^{*}$ OWAS & & $\mathbf{n}$ & $\%$ \\
\hline \multirow[t]{4}{*}{ Sırt } & Düz & 114 & 53,5 \\
\hline & Eğik & 81 & 38,0 \\
\hline & Çevrilmiş veya bir yana eğrilmiş & 6 & 2,8 \\
\hline & Çevrilmiş ve bükülmüş ya da eğilmiş & 12 & 5,7 \\
\hline \multirow[t]{3}{*}{ Üst ekstremite } & Her iki kol omuz hizasının altında & 180 & 84,5 \\
\hline & Bir kol omuz hizasının üstünde & 12 & 5,6 \\
\hline & Her iki kol omuz hizasının üstünde & 21 & 9,9 \\
\hline \multirow[t]{4}{*}{ Alt ekstremite } & Oturma & 190 & 89,2 \\
\hline & Dik olarak iki bacak üzerinde ayakta durma & 11 & 5,2 \\
\hline & Dik olarak tek bacak üzerinde ayakta durma & 4 & 1,8 \\
\hline & Yürüme & 8 & 3,8 \\
\hline \multirow[t]{3}{*}{ Baş } & Öne eğilmiş & 103 & 48,4 \\
\hline & $45^{0}$ ile yana eğilmiş & 84 & 39,4 \\
\hline & Arkaya eğilmiş & 26 & 12,2 \\
\hline \multirow[t]{4}{*}{ Yük kaldırma } & Yük kaldırmıyor & 190 & 89,2 \\
\hline & 10 kg' ın altında & 7 & 3,3 \\
\hline & 10 ile $20 \mathrm{~kg}$ arasında & 4 & 1,9 \\
\hline & 20 kg' dan fazla & 12 & 5,6 \\
\hline
\end{tabular}

*OWAS: Ovako Çalışma Duruşları Analiz Sistemi

Tablo 4. Ofis çalışanlarının Cornell Kas İskelet Sistemi Rahatsızlığı Anketi analiz sonuçları

\begin{tabular}{lccc}
\hline & $\begin{array}{c}\text { Ağrı sıklığı (kez/hafta) } \\
\text { Ort. } \pm S S\end{array}$ & $\begin{array}{c}\text { Ağrı şiddeti } \\
\text { Ort. } \pm \text { SS }\end{array}$ & $\begin{array}{c}\text { Işin engellenmesi } \\
\text { Ort. } \pm S S\end{array}$ \\
\hline CMDQ Omurga & $6,57 \pm 7,11$ & $3,05 \pm 4,05$ & $2,47 \pm 1,97$ \\
\hline CMDQ Alt ekstremite & $4,07 \pm 8,18$ & $2,16 \pm 3,48$ & $1,88 \pm 3,12$ \\
\hline CMDQ Üst ekstremite & $5,7 \pm 10,39$ & $2,4 \pm 3,56$ & $2,25 \pm 3,62$
\end{tabular}

(Ort: ortalama, SS: Standart Sapma, CMDQ: Cornell Kas İskelet Sistemi Rahatsızlığı Anketi 
Kişisel risk faktörlerinden cinsiyet ve çalışma yılı değişkenlerinin OÖA sonuçlarına etkisi karşılaştırılmıştır (Tablo 5). Kadın ve erkeklerin verileri karşılaştııılığında kadınlarda OÖA toplam puanı (Sıra Ort. $=117,92)$ erkeklere $($ Sıra Ort. $=89,55)$ kıyasla daha yüksek olduğu saptanmıştır ( $Z=-3,307$, $p<0,05)$. Çalışma yılı risk faktörü açısından çalışma yılı 1-2 yıl arasında ve çalışma yılı 2 yıldan fazla olanlar olmak üzere 2 gruba ayrılmış katılımcıların OÖA toplam puanları, istatistiksel olarak farklılık göstermemiştir ( $Z=-1,042, p>0,05)$ (Tablo 5).

Katılımcıların OÖA ve NSP alt bölüm sonuçları gösterilmiştir (Tablo 6).

Tablo 5. Kişisel risk faktörü değişkenlerinin Oswestry Özürlülük Anketi'ne etkisi

\begin{tabular}{|c|c|c|c|c|c|c|}
\hline \multicolumn{2}{|c|}{ Kişisel risk faktörü değişkenleri } & \multirow{2}{*}{$\begin{array}{c}\begin{array}{c}\text { Sira } \\
\text { Ort }\end{array} \\
117,92\end{array}$} & \multirow{2}{*}{$\begin{array}{c}\mathbf{S T} \\
15447,50\end{array}$} & \multirow{2}{*}{$\begin{array}{c}\mathbf{U} \\
3940,50\end{array}$} & \multirow{2}{*}{$\begin{array}{r}\mathbf{Z} \\
-3,307\end{array}$} & \multirow{2}{*}{$\begin{array}{r}\mathrm{r} \\
0,001^{*}\end{array}$} \\
\hline Cinsiyet & Kadın $(n=131)$ & & & & & \\
\hline & Erkek $(n=82)$ & 89,55 & 7343,50 & & & \\
\hline \multirow{2}{*}{$\begin{array}{c}\text { Çalışma yılı } \\
\text { (yıl) }\end{array}$} & $<1-2$ yıl $(n=59)$ & 99,97 & 5898,50 & 4128,50 & $-1,042$ & 0,297 \\
\hline & $\geq 2$ yıl $(n=154)$ & 109,69 & 16892,50 & & & \\
\hline
\end{tabular}

(Sıra Ort: Sıra Ortalaması, ST: Sıra Toplamı, U: Mann Whitney U Testi, Z: Z puanı, $p^{*}<0,05$ )

Tablo 6. Ofis çalışanlarının Oswestry Özüllülük Anketi ve Nottingham Sağlık Profili alt boyut sonuçları

\begin{tabular}{lc}
\hline & Ortalama \pm SS \\
\hline OÖA & $6,21 \pm 7,61$ \\
\hline NSP enerji seviyesi & $29,56 \pm 35,26$ \\
\hline NSP ağrı & $17,04 \pm 19,72$ \\
\hline NSP fiziksel aktivite & $12,43 \pm 14,58$ \\
\hline NSP uyku & $15,77 \pm 22,13$ \\
\hline NSP emosyonel reaksiyonlar & $20,79 \pm 22,92$ \\
\hline NSP sosyal izolasyon & $7,79 \pm 18,97$
\end{tabular}

(SS: Standart Sapma, OÖA: Oswestry Özürlülük Anketi, NSP: Nottingham Sağlık Profili)

Ofis çalışanlarının OÖA ile CMDQ omurga ağrı sıklığı $(r=0,462, p=0,000)$, ağrı şiddeti $(r=0,483$, $p=0,000)$, ağrıya bağlı işin engellenmesi $(r=0,505$, $p=0,000)$; CMDQ alt ekstremite ağrı sıklığı $(r=0,352$, $p=0,000)$, ağrı şiddeti $(r=0,328 p=0,000)$, ağrıya bağı işin engellenmesi $(r=0,379, p=0,000)$; CMDQ üst ekstremite ağrı sıkıı̆ı $(r=0,361, p=0,000)$, ağrı şiddeti $(r=0,363, p=0,000)$ ve ağrıya bağlı işin engellenmesi $(r=0,383, p=0,000)$ alt parametreleri arasında pozitif yönlü zayıf-orta derecede anlamlı ilişkiler bulunmuştur (Tablo 7).

Ofis çalışanlarının OÖA ile NSP sosyal izolasyon alt bölümü arasında $(r=0,159, p=, 020)$ pozitif yönlü anlamlı ilişki bulunmuştur. OÖA ile NSP'nin enerji seviyesi $(r=0,47, p=0,000)$, ağrı $(r=0,671, p=0,000)$, fiziksel hareketlilik $(r=0,549, p=0,000)$, uyku $(r=0,34$, $p=0,000)$ ve emosyonel reaksiyonlar $(r=0,432$, $p=0,000)$ alt bölümleri arasında pozitif yönlü çok zayıf-yüksek derecede anlamlı ilişkiler bulunmuştur (Tablo 7).

Ofis çalışanlarının NSP enerji seviyesi alt bölümü ile, CMDQ omurga ağrı sıklığı $(r=0,439$, $p=0,000)$ ağrı şiddeti $(r=0,458, p=0,000)$, ağrıya bağlı işin engellenmesi $(r=0,458, p=0,000)$; $C M D Q$ alt ekstremite ağrı sıklığı $(r=0,404, p=0,000)$ ağrı şiddeti $(r=0,403, p=0,000)$, ağrıya bağlı işin engellenmesi $(r=0,425, p=0,000)$; CMDQ üst ekstremite ağrı sıklığı $(r=0,372, p=0,000)$ ağrı şiddeti $(r=0,362, p=0,000)$, ağrıya bağı işin engellenmesi $(r=0,365, p=0,000)$ alt parametreleri arasında pozitif yönlü zayıf-orta derecede anlamlı ilişkiler bulunmuştur (Tablo 7).

Ofis çalışanlarının NSP ağrı alt bölümü ile, CMDQ omurga ağrı sıklığı $(r=0,418, p=0,000)$ ağrı şiddeti $(r=0,439, \quad p=0,000)$, ağrıya bağı işin engellenmesi $(r=0,463, \quad p=0,000) ; \quad C M D Q$ alt ekstremite ağrı sıklığı $(r=0,428, p=0,000)$ ağrı şiddeti $(r=0,403, p=0,000)$, ağrıya bağlı işin engellenmesi $(r=0,43, p=0,000)$; CMDQ üst ekstremite ağrı sıklığı $(r=0,396, p=0,000)$ ağrı şiddeti $(r=0,369, p=0,000)$, ağrıya bağı işin engellenmesi $(r=0,385, p=0,000)$ alt parametreleri arasında pozitif yönlü zayıf-orta derecede anlamlı ilişkiler bulunmuştur (Tablo 7). 
Tablo 7. Oswestry Özürlülük Anketi, Nottingham Sağlık Profili, Cornell Kas İskelet Sistemi Rahatsızlığı Anketi, Ovako Çalışma Postürü Analiz Sistemi ilişkileri

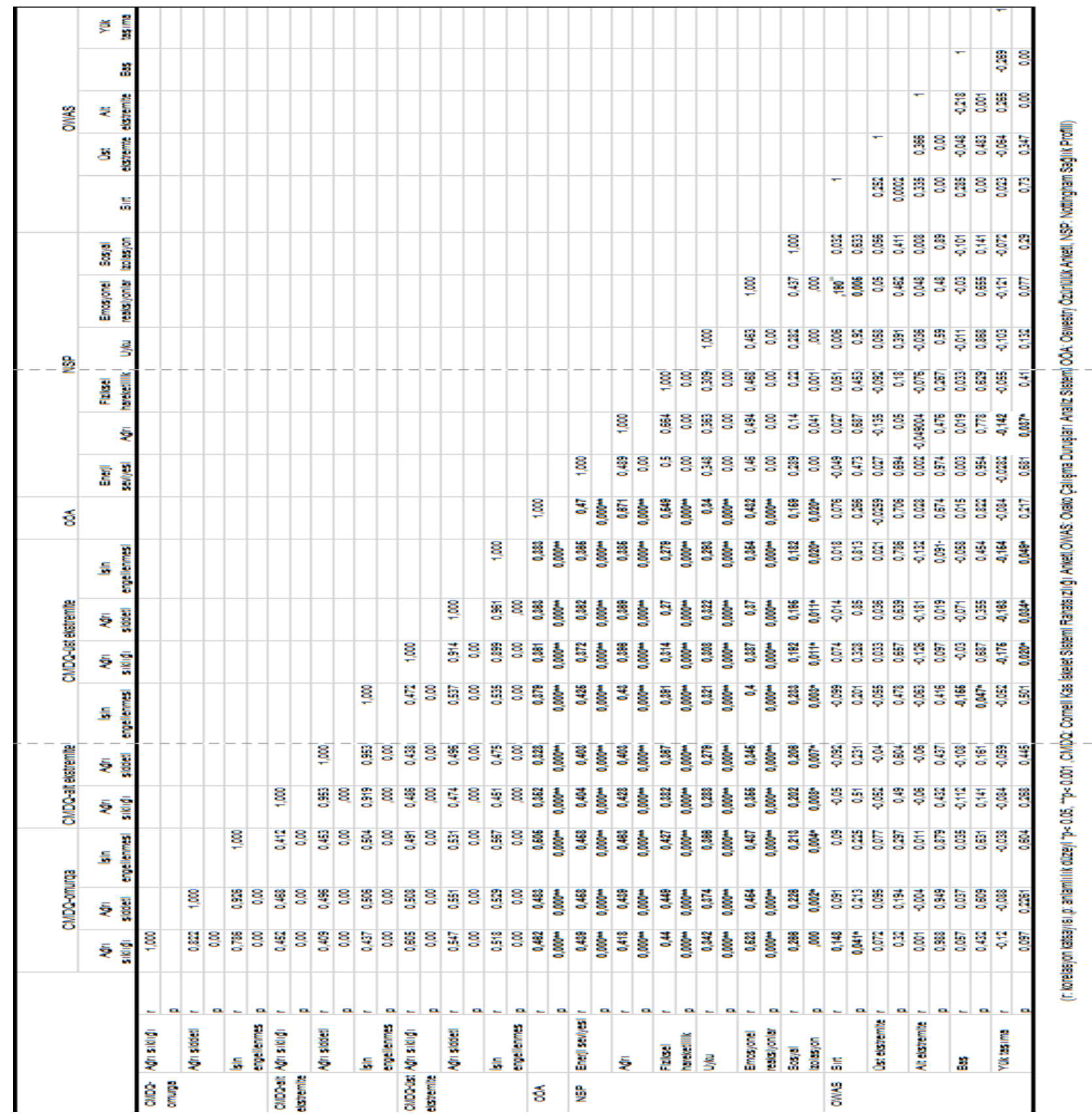

Ofis çalışanlarının NSP fiziksel hareketlilik alt bölümü ile, CMDQ omurga ağrı sıklığı $(r=0,44$, $p=0,000)$ ağrı şiddeti $(r=0,449, p=0,000)$, ağrıya bağlı işin engellenmesi ( $r=0,427, p=0,000) ; C M D Q$ alt ekstremite ağrı sıklığı $(r=0,382, p=0,000)$ ağrı şiddeti $(r=0,367, p=0,000)$, ağrıya bağlı işin engellenmesi $(r=0,391, p=0,000)$; CMDQ üst ekstremite ağrı sıklığı $(r=0,314, p=0,000)$ ağrı şiddeti $(r=0,27, p=0,000)$, ağrıya bağlı işin engellenmesi $(r=0,279, p=0,000)$ alt parametreleri arasında pozitif yönlü zayıf-orta

derecede anlamlı ilişkiler bulunmuştur (Tablo 7).

Ofis çalışanlarının NSP uyku alt bölümü ile, CMDQ omurga ağrı sıklığı $(r=0,342, p=0,000)$ ağrı şiddeti $(r=0,374, \quad p=0,000)$, ağrıya bağlı işin engellenmesi $(r=0,366, \quad p=0,000) ; \quad C M D Q$ alt ekstremite ağrı sıklığı $(r=0,288, p=0,000)$ ağrı şiddeti $(r=0,279, p=0,000)$, ağrıya bağlı işin engellenmesi $(r=0,321, p=0,000)$; CMDQ üst ekstremite ağrı sıklığı $(r=0,308, p=0,000)$ ağrı şiddeti $(r=0,322, p=0,000)$, ağrıya bağlı işin engellenmesi $(r=0,293, p=0,000)$ alt 
parametreleri arasında pozitif yönlü zayıf derecede anlamlı ilişkiler bulunmuştur (Tablo 7).

Ofis çalışanlarının NSP emosyonel reaksiyonlar alt bölümü ile, CMDQ omurga ağrı sıklığı $(r=0,523$, $p=0,000)$ ağrı şiddeti $(r=0,454, p=0,000)$, ağrıya bağlı işin engellenmesi $(r=0,437, p=0,000) ; C M D Q$ alt ekstremite ağrı sıklığı $(r=0,355, p=0,000)$ ağrı şiddeti $(r=0,345, p=0,000)$, ağrıya bağlı işin engellenmesi $(r=0,400, p=0,000)$; CMDQ üst ekstremite ağrı sıklığ $(r=0,387, p=0,000)$ ağrı şiddeti $(r=0,370, p=0,000)$, ağrıya bağlı işin engellenmesi $(r=0,354, p=0,000)$ alt parametreleri arasında pozitif yönlü zayıf-orta derecede anlamlı ilişkiler bulunmuştur (Tablo 7).

Ofis çalışanlarının NSP sosyal izolasyon alt bölümü ile, CMDQ omurga ağrı sıklığı $(r=0,266$, $p=0,000$ ) arasında pozitif yönlü ileri derecede anlaml ilişki bulunmuştur. Ayrıca ofis çalışanlarının NSP sosyal izolasyon alt bölümü ile, CMDQ omurga ağrı şiddeti $(r=0,226, \quad p=0,002)$, ağrıya bağlı işin engellenmesi $(r=0,213, \quad p=0,004) ; \quad C M D Q$ alt ekstremite ağrı sıklığı $(r=0,202, p=0,008)$ ağrı şiddeti $(r=0,206, p=0,007)$, ağrıya bağlı işin engellenmesi $(r=0,233, p=0,003)$; CMDQ üst ekstremite ağrı sıklığı $(r=0,192, p=0,011)$ ağrı şiddeti $(r=0,195, p=0,011)$, ağrıya bağlı işin engellenmesi $(r=0,182, p=0,020)$ alt parametreleri arasında pozitif yönlü çok zayıf-zayıf anlamlı ilişkiler bulunmuştur (Tablo 7).

Diğer yandan OWAS sırt ile CMDQ omurgada ağrı sıklığı $(r=0,148, p=0,041)$ ve NSP'nin emosyonel reaksiyonlar alt parametresi $(p=0,190, r=0,005)$ arasında pozitif yönlü, OWAS yük taşıma ile CMDQ üst eksremitede ağrı sıklığı $(r=0,175, p=0,021)$, şiddeti $(r=0,163, p=0,035)$ ve ağrıya bağlı işin engellenmesi ( $r=0,154, p=0,049)$ ve NSP ağrı alt bölümü ( $r=-0,155 p=0,047)$; OWAS baş ile CMDQ alt ekstremite ağrıya bağlı işin engellenmesi ( $r=-$ $0,155, p=0,047$ ) arasında da negatif yönlü çok zayıf anlamlı ilişki bulunmuştur (Tablo 7).

\section{TARTIŞMA}

Bu çalışma, ofis çalışanlarının çalışma postürü, kas iskelet sistemi rahatsızlıkları, bel ağrısına bağlı özürlülük düzeyi, sağlıkla ilgili yaşam kalitesinin incelenmesi ve aralarındaki ilişkinin belirlenmesi amacıyla yapılmıştır.

Swartz AM ve ark'.nın yaptıkları çalışmada ofis çalışanlarının oturma süresi \% 66 olarak bildirilmiştir (Swartz, Rote, Welch ve ark, 2014). Çalışmamızda da katılımcıların \%60,1'inin günlük çalışma süresinin, 8 saat ve üzeri, sabit oturma süresinin ise 4,1-8 saat arası olduğu tespit edilmiştir(Tablo 1). Buna göre katılımcıların, büyük çoğunluğunun gün içerisinde statik oturma postüründe, uzun süreler çalıştığı ve sedanter davranış gösterdikleri sonucuna varılabilir. Uzun süreli oturma pozisyonunun, bel ağrısının ortaya çıkması için risk faktörü olduğu belirtilmiştir (Gupta, Christiansen, Hallman ve ark, 2015; Corlett, 2006). Danimarka'da temizlik, taşıma ve üretim departmanlarında çalışan usta ve usta başlarında yapılan geniş ölçekli bir çalışmada daha uzun süreler oturmanın boyun ve omuz ağrısı ile ilişkili olduğu sonucuna varılmıştır (Hallman, Gupta, Heiden ve ark, 2016). Uzun süre oturma gerektiren veya uzun süreli belirli bir pozisyonda kalmayı gerektiren mesleklerde bel ağrısı riskinin arttığı bildirilmektedir (Sarıdoğan-Eryavuz, 2000; Eryavuz ve Akkan, 2003; Omokhodion ve Sanya, 2003; Hopayian ve Notley, 2014). Ayakta durma ve uzanma ile kıyaslandığında oturma sırasında disklere binen yükün daha fazla olması, ayrıca uzun süre hareketsiz kalmanın diskin beslenmesini bozduğu belirtilmektedir (Nachemson, 1981; McGill, Hughson \& Parks, 2000). Ariens ve ark.'ı ofis çalışanlarında oturma pozisyonunda kalma süresi ile boyun ağrısı arasında pozitif yönlü ilişki olduğunu, oturma sırasında yanlış postürün (çalışma süresinin \%70'inden fazlasını 20 derecelik boyun fleksiyonu pozisyonunda geçirmek) boyun ağrısı riskini arttırdığı bildirilmiştir (Ariëns, Bongers, Douwes, ve ark, 2001). Çalışmamızda OWAS sonuçlarına göre katılımcıların \% 48,4'ünün başları öne eğilmiş çalışma postüründe oturdukları, ayrıca CMDQ omurga (boyun, sırt ve bel) bölümünün ağrı sıklığı ortalamasına göre haftada 6,57 \pm 7,11 kez omurgaya ait ağrı hissettikleri tespit edilmiştir. Buradan anlaşılacağı gibi katılımcıların yarısına yakın bir bölümünün (\% 48.4'ünün) çalışma ortamında boyun öne eğilmiş pozisyonda statik oturma postüründe, 4,1-8 saat arası sabit oturma süresinde oturuyor olmaları, daha sıklıkla omurga ait ağrı hissetmelerine sebep olmuş olabilir. Ancak bu ağrının sıklığının ne kadarlık bir bölümünün boyun bölgesine ait olduğu sonucuna varılamamıştır. Çalışmamızın zayıf yönü, bel ağrısına bağlı özürlülük düzeyini OÖA ile değerlendirsek de, boyun ağrısına bağlı özürlülük düzeyine yönelik fonksiyonel bir ölçek kullanmamış olmamızdır. Bu sebeple katılımcıları, literatürde sıklıkla kullanılan Northwick Park Boyun Ağrısı Anketi (Leak, Cooper, Dyer ve ark, 1994) ile değerlendirmemizin gerekli olduğu düşünüyoruz.

Ofis çalışanlarının uzun süre statik oturma pozisyonunda kalan, hareketliliğin azaldığı mesleki aktivite sırasında kol, el bileği, dirsek kasları gibi sınırlı bir grup kası kullanan bu yüzden de bozulmuş vücut postürü geliştirmeye aday bir meslek grubu olduğu belirtilmektedir. Bu durumların kas iskelet sisteminde problemlere yol açarak ağrıya neden 
olabileceği ve yaşam kalitesinde azalmaya yol açabileceği bildirilmektedir (del pazo Cruz, Gusi, Adsuar ve ark, 2013). Çalışmamızda katılımcıların CMDQ sonuçlarında, başta omurga $(6,57 \pm 7,11)$ olmak üzere üst ekstremite $(5,7 \pm 10,39)$ ve alt ekstremite $(4,07 \pm 8,18)$ ağrı sıklıklarının (kez/hafta) yüksek olduğu saptanmıştır. Bu sonuç kas iskelet sistemine ilişkin rahatsızlıkların ofis çalışanlarının evrensel sorunu olduğunu göstermektedir. Bu çalışma sonucuna göre ofis çalışanlarının alt ekstremitelerinde de sık denilebilecek ağrı şikâyetlerinin olduğu belirlenmiştir. Ofis çalışanlarına yönelik değerlendirme ve önerilerde alt ekstremitelerin de etkilenebileceği dikkate alınmalıdır. Omurga, üst ekstremite ve alt ekstremitede görülen ağrının şiddeti ve işin engellenmesi oranı benzerlik göstermekte olup, ağrı vücudun neresinde olursa olsun işi engelleme intimali var görünmektedir.

OWAS ile değerlendirdiğimiz ergonomik sonuçlarımız ise sırt pozisyonlarının genelde düz veya eğik, üst ekstremite duruşlarının normal olduğunu, katılımcıların genelde oturma pozisyonunda, başın öne eğilmiş veya 450 yana eğilmiş pozisyonda olduklarını göstermektedir. Sonuçlar bir bütün olarak incelendiğinde katılımcıların yarısında çalışma sırasında izlenen sırt ve baş postürünün bozuk olduğu ve çalışma koşullarına uygun ergonomik düzenlemelere ihtiyaç duyulduğu anlaşılmaktadır.

Çalışmamızda, sağlıkla ilgili yaşam kalitesi ile tüm vücut ağrı sıklığı, şiddeti, ağrıya bağlı işin engellenmesi ve bel ağrısı arasında anlamlı ilişkiler bulunmuştur. Buna göre ofis çalışanlarında işi engelleyen parametrelerden biri bel ağrısı olarak saptanmıştır. Bu bulgu Dünya Sağlık Örgütü (Whoqol Group, 1994) tarafından "bireyin, gerek kültürel ve içinde bulunduğu ortamın değer yargıları, gerekse kendi hedefleri, beklentileri, standartları ve ilgileri bağlamında, hayatta kendi durumunu algılama biçimi" olarak tanımlanan yaşam kalitesinin azalmasında ağrının önemli bir etken olduğunu desteklemektedir.

Çalışmamızda katılımcıların çalışma yılının OÖA'ya etkisi incelendiğinde, bel ağrısına bağlı özürlülük düzeyine çalışma yılının etki etmediği görülmektedir. Ancak çalışmamızda çok uzun yıllar ofis çalışanı olarak çalışan katılımcıların bulunmaması bir limitasyon olarak belirtilebilir.

$\mathrm{Bu}$ çalışmanın katılımcılarının uzun çalışma saatleri ve sabit oturma sürelerinin uzunluğu dikkat çekicidir. Çalışmamızın çıktılarından birisi ofis çalışanlarının ergonomik düzenlemeye intiyaç duymasıdır. Ofis çalışanları içerisinde kadınlarda bel ağrısına bağlı özürlülüğün daha fazla olması bu konuda kadınlara yönelik özel analizler içeren çalışmalara gereksinimi ortaya koymuştur. Ayrıca tüm ofis çalışanlarında bel ağrısına bağlı özürlülük, kas iskelet sistemine bağlı ağrı ve sağlıkla ilgili yaşam kalitesi gibi faktörlerin ilişkili bulunması tüm bu faktörlerin bütüncül bir bakış açısı ile ele alınması gerektiğini gösterir. Ofis çalışanları için cinsiyeti dikkate alan ergonomik düzenlemeyi de içeren, bel ağrısına bağlı özürlülüğü azaltan bütüncül bir yaklaşımın ortaya koyulması daha sonraki hedefler olarak düşünülmüştür. Kas iskelet sistemi değerlendirme sonuçlarımız omurgada ve üst ekstremitelerde ağrı sıklığının daha fazla olduğunu göstermiştir. İlişki analizleri incelendiğinde bel ağrısına bağlı özürlülük ile kas iskelet sistemine bağlı ağrının ilişkili olduğu ve bu durumun işi engellediği görülmüştür. Ayrıca bel ağrısına bağlı özürlülük sağlıkla ilgili yaşam kalitesi ile de ilişkili bulunmuştur.

Illerde yapılacak çalışmalarda; daha fazla sayıda ofis çalışanına, farklı değerlendirme ölçekleri kullanılarak yapılan, uygun ergonomik düzenlemeler, düzenli egzersiz programları ve çalışma dışı fiziksel aktivite alışkanlığının kazandırılmasını kapsayan uygulamaların yapılması, bu programların uzun süreli sonuçlarının takibi, katılımcıların programa uyumu, çalışma verimliliğine ve yaşam kalitesine etkileri araştırılmalıdır.

\section{Kaynaklar}

Ardahan, M., \& Simsek, H. (2016). Analyzing musculoskeletal system discomforts and risk factors in computer-using office workers. Pak J Med Sci, 32(6), 1425.

Ariëns, G. A. M., Bongers, P. M., Douwes, M., Miedema, M. C., Hoogendoorn, W. E., van der Wal, G., \& van Mechelen, W. (2001). Are neck flexion, neck rotation, and sitting at work risk factors for neck pain? Results of a prospective cohort study. Occupational and Environmental Medicine, 58(3), 200-207.

Blümel, J. E., Arteaga, E., Mezones-Holguín, E., Zúñiga, M. C., Witis, S., Vallejo, M. S., ... \& Mostajo, D. (2017). Obesity is associated with a higher prevalence of musculoskeletal pain in middle-aged women. Gynecol Endocrinol, 33(5), 378-382.

Cho, C. Y., Hwang, Y. S., \& Cherng, R. J. (2012). Musculoskeletal symptoms and associated risk factors among office workers with high workload computer use. J Manipulative Physiol Ther 35(7), 534-540.

Corlett, E. N. (2006). Background to sitting at work: researchbased requirements for the design of work seats. Ergonomics, 49(14), 1538-1546.

del Pozo-Cruz, B., Gusi, N., Adsuar, J. C., del Pozo-Cruz, J., Parraca, J. A., \& Hernandez-Mocholí, M. (2013). Musculoskeletal fitness and health-related quality of life 
characteristics among sedentary office workers affected by sub-acute, non-specific low back pain: a crosssectional study. Physiotherapy, 99(3), 194-200.

Erdinc, O., Hot, K., \& Ozkaya, M. (2011). Turkish version of the Cornell Musculoskeletal Discomfort Questionnaire: crosscultural adaptation and validation. Work, 39(3), 251-260.

Eryavuz, M., \& Akkan, A. (2003). Fabrika çalışanlarında bel ağrısı risk faktörlerinin değerlendirilmesi. Turk J Phys Med Rehab, 49(5).

Fairbank, J. C., \& Pynsent, P. B. (2000). The Oswestry disability index. Spine, 25(22), 2940-2953.

Gerr, F., Marcus, M., \& Monteilh, C. (2004). Epidemiology of musculoskeletal disorders among computer users: lesson learned from the role of posture and keyboard use. J Electromyogr Kinesiol, 14(1), 25-31.

Gerr, F., Monteilh, C. P., \& Marcus, M. (2006). Keyboard use and musculoskeletal outcomes among computer users. J Occup Rehabil, 16(3), 259.

Gilkey, D. P., Keefe, T. J., Bigelow, P. L., Herron, R. E., Duvall, K., Hautaluoma, J. E., ... \& Sesek, R. (2007). Low back pain among residential carpenters: ergonomic evaluation using OWAS and 2D compression estimation. Int J Occup Saf Ergon, 13(3), 305-321.

González, V. M., \& Condón, H. M. (2000). Disability from low back pain in Spain. Med Clin, 114(13), 491-492.

Gupta, N., Christiansen, C. S., Hallman, D. M., Korshøj, M., Carneiro, I. G., \& Holtermann,

A. (2015). Is objectively measured sitting time associated with low back pain? A cross-sectional investigation in the NOMAD study. PLoS One, 10(3), e0121159.

Hallman, D. M., Gupta, N., Heiden, M., Mathiassen, S. E., Korshøj, M., Jørgensen, M. B., \& Holtermann, A. (2016). Is prolonged sitting at work associated with the time course of neck-shoulder pain? A prospective study in Danish blue-collar workers. BMJ open, 6(11), e012689.

Hedge, A. (1994). Cornell musculoskeletal discomfort questionnaire: human factors and ergonomics laboratory at Cornell University. Female. January 10, 2015. http://www. ergo. human. cornell. edu.

Hopayian, K., \& Notley, C. (2014). A systematic review of low back pain and sciatica patients' expectations and experiences of health care. Spine J, 14(8), 1769-1780.

Hoy, D., Brooks, P., Blyth, F., \& Buchbinder, R. (2010). The epidemiology of low back pain. Best Pract Res Clin Rheumatol, 24(6), 769-781.

Hussain, S. M., Urquhart, D. M., Wang, Y., Shaw, J. E., Magliano, D. J., Wluka, A. E., \& Cicuttini, F. M. (2017). Fat mass and fat distribution are associated with low back pain intensity and disability: results from a cohort study. Arthritis Res. Ther., 19(1), 26

Janwantanakul, P., Pensri, P., Moolkay, P., \& Jiamjarasrangsi, W. (2011). Development of a risk score for low back pain in office workers-a cross-sectional study. BMC Musculoskelet Disord, 12(1), 23.

Johnston, V., Jull, G., Souvlis, T., \& Jimmieson, N. L. (2008) Neck movement and muscle activity characteristics in female office workers with neck pain. Spine, 33(5), 555563.

Kim, D., Park, S., Yang, D., Cho, M., Yoo, C., Park, J., ... \& Yang, Y. (2015). The relationship between obesity and health-related quality of life of office workers. J Phys Ther Sci, 27(3), 663-666.
Kücükdeveci, A. A., McKenna, S. P., Kutlay, S., Gürsel, Y., Whalley, D., \& Arasil, T. (2000). The development and psychometric assessment of the Turkish version of the Nottingham Health Profile. Int J Rehabil Res, 23(1), 3138.

Leak, A. M., Cooper, J., Dyer, S., Williams, K. A., TurnerStokes, L., \& Frank, A. O. (1994). The Northwick Park Neck Pain Questionnaire, devised to measure neck pain and disability. Rheumatology, 33(5), 469-474.

Lee, S., Park, M. H., \& Jeong, B. Y. (2017). Gender differences in public office workers' satisfaction, subjective symptoms and musculoskeletal complaints in workplace and office environments. Int J Occup Saf Ergon, 1-6.

McGill, S. M., Hughson, R. L., \& Parks, K. (2000). Lumbar erector spinae oxygenation during prolonged contractions: implications for prolonged work. Ergonomics, 43(4), 486-493.

Nachemson, A. L. (1981). Disc pressure measurements. Spine, 6(1), 93-97.

Omokhodion, F. O., \& Sanya, A. O. (2003). Risk factors for low back pain among office workers in Ibadan, Southwest Nigeria. Occup Med, 53(4), 287-289.

Özel, E., \& Çetik, O. (2010). Mesleki görevlerin ergonomik analizinde kullanılan araçlar ve bir uygulama örneği. DPÜ Fen Bilimleri Enstitüsü Dergisi, 22 (8), 41-56

Rodriguez-Blanco, T., Fernández-San-Martin, I., BalaguéCorbella, M., Berenguera, A., Moix, J., Montiel-Morillo, E., ... \& Roura-Olivan, M. (2010). Study protocol of effectiveness of a biopsychosocial multidisciplinary intervention in the evolution of non-specific sub-acute low back pain in the working population: cluster randomised trial. BMC Health Serv Res, 10, 12-12.

Saridoğan, M. E. (2000). Bel ağrısı nedenleri ve epidemiyolojisi. Modern Tıp Seminerleri. Ankara, 19-29.

Schaller, A., \& Froboese, I. (2014). Movement coaching: study protocol of a randomized controlled trial evaluating effects on physical activity and participation in low back pain patients. BMC Musculoskelet Disord, 15(1), 391.

Solidaki, E., Chatzi, L., Bitsios, P., Markatzi, I., Plana, E., Castro, F., ... \& Kogevinas, M. (2010). Work related and psychological determinants of multi-site musculoskeletal pain. Scand J Work Environ Health, 36(1), 54.

Swartz, A. M., Rote, A. E., Welch, W. A., Maeda, H., Hart, T. L., Cho, Y. I., \& Strath, S. J. (2014). Peer Reviewed: Prompts to Disrupt Sitting Time and Increase Physical Activity at Work, 2011-2012. Prev Chronic Dis, 11.

Szeto, G. P. Y., Straker, L. M., \& O'Sullivan, P. B. (2009). Neck-shoulder muscle activity in general and taskspecific resting postures of symptomatic computer users with chronic neck pain. Man Ther, 14(3), 338-345.

Yakut, E., Düger, T., Öksüz, Ç., Yörükan, S., Üreten, K., Turan, D., ... \& Yakut, Y. (2004). Validation of the Turkish version of the Oswestry Disability Index for patients with low back pain. Spine, 29(5), 581-585.

Whoqol Group. (1994). The development of the World Health Organization quality of life assessment instrument (the WHOQOL). In Quality of life assessment: International perspectives (pp. 41-57). Berlin, Heidelberg: Springer. 